\title{
Potential role of a cognitive rehabilitation program following left temporal lobe epilepsy surgery
}

\author{
Reabilitação neuropsicológica em pacientes com epilepsia submetidos à lobectomia \\ temporal dominante
}

\author{
Camila de Vasconcelos Geraldi1,2, Sara Escorsi-Rosset ${ }^{1}$, Pamela Thompson ${ }^{2,3}$, Ana C. Gargaro Silva ${ }^{1}$, \\ Américo Ceiki Sakamoto
}

\begin{abstract}
Research into memory and epilepsy has focused on measuring problems and exploring causes with limited attention directed at the role of neuropsychological rehabilitation in alleviating post-operative memory difficulties. Objectives: To assess the effects of a memory rehabilitation program in patients with left temporal lobe epilepsy following surgery. Methods: Twenty-four patients agreed to participate and 18 completed the study; nine received memory rehabilitation while nine had no input and were designated as controls. Verbal learning efficiency, naming abilities, memory subjective ratings, ecological activity measures and a language fMRI paradigm were used as outcome measures. Results: Improved verbal learning and naming test performance, increase in memory strategy use and improved self-perception were observed following the rehabilitation. Changes in fMRI activation patterns were seen in the rehabilitation group over the long term. Conclusion: The findings support the potential role of a cognitive rehabilitation program following left temporal lobe surgery.
\end{abstract}

Keywords: epilepsy, temporal lobe; memory; neurologic rehabilitation; anterior temporal lobectomy.

\section{RESUMO}

As publicações na área de epilepsia e memória se focam em mensurar prejuízos e investigar causas, com poucos dados sobre reabilitação neuropsicológica em pacientes pós-cirúrgicos. Objetivos: Avaliar os efeitos da reabilitação neuropsicológica em pacientes submetidos a lobectomia temporal dominante. Métodos: Vinte e quatro pacientes iniciaram o estudo, apenas dezoito o concluíram, dos quais 9 foram participantes de sessões de reabilitação com enfoque em memória. Todos os participantes foram avaliados quanto a autopercepção de dificuldades de memória; ao uso de estratégias para minimizar tais dificuldades; a habilidade de nomeação e a aprendizagem verbal e foram submetidos à ressonância magnética funcional. Resultados: Foi encontrado efeito significativo da reabilitação neuropsicológica na autopercepção de dificuldades de memória; no uso de estratégias compensatórias; na aprendizagem verbal e na nomeação. Alterações no padrão de ativação na RMf foram observadas no grupo submetido a reabilitação. Conclusão: A reabilitação neuropsicológica pode beneficiar pacientes submetidos a lobectomia temporal antero-mesial dominante com prejuízos de memória.

Palavras-chave: epilepsia do lobo temporal; memória; reabilitação neurológica; lobectomia temporal anterior.

Memory deficits in people with temporal lobe epilepsy (TLE) have been widely reported and memory decline is a well-established surgical outcome, particularly following dominant temporal lobe resections. Memory difficulties can have far ranging effects that affect academic and work performance but also can cause considerable personal distress. Research into memory and epilepsy has focused on measuring problems and exploring causes with limited attention directed to the role of neuropsychological rehabilitation ${ }^{1}$. Cognitive rehabilitation comprises a range of techniques, and research in patients with various brain injuries and pathologies has provided some support for its efficacy ${ }^{2,3,4,5,6,7}$.

The evidence base for memory rehabilitation in epilepsy is limited particularly in temporal lobe surgical cases, a high-risk group. Well-controlled trials are few and data on generalization to daily activities and the persistence of effects are sparse ${ }^{1,8}$. Existing reports have been encouraging ${ }^{8,9}$. Unfortunately few studies describe the rehabilitation process sufficiently ${ }^{8}$, while for others memory rehabilitation forms part of a more extensive set of interventions such that it is impossible to identify specific effects ${ }^{10}$.

\footnotetext{
${ }^{1}$ Universidade de São Paulo, Faculdade de Medicina de Ribeirão Preto, Departamento de Neurociências e Ciências do Comportamento, Ribeirão Preto SP, Brasil; ${ }^{2} \mathrm{UCL}$ Institute of Neurology, Department of Clinical and Experimental Epilepsy, London, UK;

${ }^{3}$ Epilepsy Society Research Centre, Buckinghamshire, UK.

Correspondence: Camila de Vasconcelos Geraldi; Departamento de Neurociências e Ciências do Comportamento, FMRP / USP, Centro de Cirurgia de Epilepsia (CIREP) 40 andar; Av Bandeirantes, 3900; 14048-900 Ribeirão Preto SP, Brasil; E-mail: camigeraldi@hotmail.com

Conflict of interest: There is no conflict of interest to declare.

Received 15 September 2016; Received in final form 01 February 2017; Accepted 14 February 2017.
} 
Which features of the rehabilitation programs contribute to the cognitive gains reported and the mechanism of underlying these changes is uncertain but available evidence suggests it can be effective. If memory rehabilitation has positive effects then this would provide support for inclusion in surgical programs and further research is of considerable clinical relevance. This study aimed to assess the effectiveness of memory rehabilitation for left TLE patients following surgery and utilized an fMRI paradigm to assess for changes in brain function in association with rehabilitation.

\section{METHODS}

\section{Participants}

Patients with epilepsy, who had undergone selective left temporal lobe surgery at least six months previously, were recruited. Participants were at least 16 years old and were right handed. No participant had a learning disability (IQ < 70) or a psychiatric history or any evidence of anti-epileptic drug toxicity.

Sixty-two patients met the study criteria but only 24 agreed to participate.

Thirteen people were assigned to the active treatment program (the rehabilitation group) and 11 to the control group. Unfortunately, participant selection was not random, as those in the control group were people who were unable to commit to the time and travel requirements of the treatment program.

Written informed consent was obtained from all participants. This study was approved by the ethics committee (process number 9968/2009).

Eighteen people completed the study, nine in the rehabilitation group and nine in the control group. Six patients did not complete the entire program, four in the rehabilitation group and two in the control group. Five failed to attend one of the appointments for the fMRI scan and the cognitive reassessment. The reasons for discontinuing the program prematurely were lack of time due to starting a new job $(n=1)$, other personal commitments $(n=2)$, depression $(n=1)$ and lack of resources for traveling to the hospital $(n=2)$.

There were no significant differences between the control and rehabilitation groups on demographic or epilepsy related variables (Table 1). Both groups experienced good surgery outcomes (Engel I and II).

\section{Procedure}

At the study onset, both groups completed tests of memory, naming, a memory complaints questionnaire and an ecological memory measure. Each participant also underwent an fMRI study.

The rehabilitation group then received eight cognitive rehabilitation sessions, delivered on an individual basis, once a week for two months. Thirty days following the completion
Table 1. Demographic and clinical characteristics of the rehabilitation and control groups.

\begin{tabular}{|c|c|c|}
\hline Variable & Control & Rehabilitation \\
\hline \multicolumn{3}{|l|}{ Gender } \\
\hline Male/Female & $4 / 5$ & $4 / 5$ \\
\hline Age (years) & $44(14)$ & $41(14.4)$ \\
\hline Education (years) & $7.2(29)$ & $7.9(32)$ \\
\hline \multicolumn{3}{|l|}{ Occupation } \\
\hline Employed & 5 & 2 \\
\hline Unemployed & 3 & 6 \\
\hline Student & 1 & 1 \\
\hline IQ & $86.44(9.7)$ & $85.11(5.4)$ \\
\hline Age of epilepsy onset & $10.44(5.43)$ & $9.7(5.98)$ \\
\hline Years since surgery & $5.2(4.2)$ & $5.3(4.5)$ \\
\hline \multicolumn{3}{|l|}{ Engel } \\
\hline I & 6 & 7 \\
\hline II & 3 & 2 \\
\hline \multicolumn{3}{|l|}{ Anti-epileptic drugs } \\
\hline Carbamazepine & 8 & 9 \\
\hline Clobazam & 1 & 0 \\
\hline Lamotrigine & 1 & 2 \\
\hline
\end{tabular}

of the program, they had a second fMRI study and repeated the cognitive tests and questionnaire.

The control group underwent cognitive retesting and a second fMRI study at an interval of two months but received no rehabilitation. During these two months, they were not seen at the hospital.

A third fMRI was scheduled for both groups two months after the reassessment; however, this was only possible for the rehabilitation group.

\section{Cognitive rehabilitation sessions}

Weekly sessions lasted one hour. Topics covered psycho-education about memory, and taught rehabilitation techniques focusing on attention, memory and wordfinding problems. Cognitive strategies included self-monitoring and encoding level intervention, such as semantic elaboration, prospective memory training and visual imagery ${ }^{11}$. Instruction was given in the use of external memory aids such as notes and diaries. Strategies and exercises were derived from those advocated by proponents of memory rehabilitation ${ }^{11}$. Also, homework was given at the end of each session and checked at the beginning of the next session (Table 2).

At the beginning of the second and of the third sessions, a relative or living companion attended a session on the use of memory strategies and aids in order to provide support in the home setting when needed. 


\begin{tabular}{|c|c|}
\hline Rapport: & $\begin{array}{c}\text { explain the aims of the sessions; check the patients' complaints; establish goals; explain the } \\
\text { relevance of the commitment to the sessions and timing. }\end{array}$ \\
\hline Psycho-education: & $\begin{array}{l}\text { how memory works, epilepsy and memory (drugs, surgery); age and mood influencing memory; types } \\
\text { of memory; awareness of memory function. }\end{array}$ \\
\hline Self-monitoring: & to assist participants to assess their memory in everyday settings and to apply techniques taught. \\
\hline External memory aids: & $\begin{array}{c}\text { a range of memory aids was shown and selected on an individual basis (diaries, calendars, lists, } \\
\text { notes, pill dispensers, alarms, wipe and clean memo boards, computers). }\end{array}$ \\
\hline Internal strategies: & $\begin{array}{l}\text { how to actively work with information to make it more memorable; paying attention and reducing } \\
\text { distractions;chunking to organise large information to remember making associations (semantic } \\
\text { elaboration); make a story with new information; mental pictures of the information to be } \\
\text { remembered (visual imagery); semantic elaboration (determines what property objects to be } \\
\text { remembered have in common); PQRST to increase the recall of written information; retrieval } \\
\text { strategies (alphabetical searching; retracing events, retrospection). }\end{array}$ \\
\hline Practise: & exercises in the use of strategies were incorporated in the sessions. \\
\hline Homework: & $\begin{array}{l}\text { to get the best of the strategies taught; whether they were useful and if changes had to be made; } \\
\text { homework was given in the end of each session. Adjustments to the use of strategies or other } \\
\text { difficulties were discussed. Participants were encouraged to practice regularly and to try out } \\
\text { strategies in daily life. }\end{array}$ \\
\hline
\end{tabular}

\section{Outcome measures}

\section{Objective cognitive outcomes.}

The Boston Naming Test ${ }^{12}$ was used to assess retrieval from semantic memory. The subject is required to name 60 items of increasing difficulty, presented as line drawings. The score used was the total number of items named correctly, considering spontaneous response plus semantic cues.

The Rey Auditory Verbal Learning Test ${ }^{13}$ was used to assess verbal learning and recall. The subject is read a list of 15 words over five trials. On each trial, they have to recall as many words as they can. In this study, the total number of words recalled over the learning trials was used as the measure of the memory performance (maximum score $=75$ ).

The Ecological Activity was adapted from the Five Daily Living Test, part of the Neuropsychological Assessment Battery ${ }^{14}$. This test assesses memory in a context that simulates performance in everyday life. The subject has to remember what and where in the test room the examiner hides an object. The subject is also given a name to remember, e.g. Carolina Paiva. One point is given for each correct answer resulting in a maximum score of four points. The total score was used in the analysis.

\section{Subjective memory outcomes.}

The Self Report Memory Questionnaire ${ }^{2}$ was used to assess the self-perception of memory and the strategies used by the subject in everyday settings. It consists of 28 items; 24 items concern the experience of memory failures encountered in daily life and the remaining four the use of memory support strategies. The questionnaire produces a maximum score of 96 points for the first 24 questions - four points for each correct answer; the higher the score, the poorer the memory self-perception); and 20 points for the remaining four questions (five points for each answer; the higher the score, more strategies the subject uses). The scores were analysed separately.

\section{fMRI}

A fluency paradigm to assess language networks preand post-rehabilitation provided a generic measure of brain activation involving the semantic processing system. Posterior temporal regions within a larger anteroposterior-basal temporal network have been identified in the process of word retrieval in $\mathrm{TLE}^{15}$ and word finding difficulties have been found to correlate with resting-state metabolism of the postero-infero-temporo-basal region (BA 20-37), the posterior part of superior temporal gyrus (BA39) and inferior parietal lobule (BA40) ${ }^{15}$. Several studies have demonstrated that verbal fluency paradigms are sensitive to detecting impaired functioning of the prefrontal cortex and brain interconnections, particularly of the left hemisphere ${ }^{16}$.

\section{fMRI task}

Participants underwent out-of-scanner training to maximize task compliance. The task used followed a blocked experimental design and all the stimuli were presented via a digital sound recorder. Patients were asked to think silently of as many words as possible starting with a specified letter (M, A, E, C and S- LET task) ${ }^{17}$. The whole paradigm consisted of nine blocks: five resting periods and four activations, in 30 second blocks. During the resting period the subjects were instructed to think of a "blank wall".

\section{fMRI acquisition}

The MRI data acquisition was performed on a Philips Achieva 3T XSERIES scanner. Structural T1-weighted images were obtained using a standard gradient-echo sequence MPRAGE (TR = $6 \mathrm{~ms}, \mathrm{TE}=3 \mathrm{~ms}$, matrix $256 \times 256$, $\mathrm{FOV}=256 \mathrm{~mm}, 1 \mathrm{~mm}$ slice). One set of functional echo-planar images were acquired $(\mathrm{TR} / \mathrm{TE}=3000 / 30 \mathrm{~ms}$, FOV $230 \mathrm{~mm}$, voxel vol $1.79 \times 1.79 \times 4.00 \mathrm{~mm}^{3}$, matrix dimension = $128 \times 128$ ). Functional images were processed using the software Brain 
Voyager $^{\text {mix }}$ QX (version 2.0) Brain Innovation, Maastricht, The Netherlands (Goebel et al., 2006) ${ }^{18}$. The fMRI data sets were obtained in EPI-BOLD sequences and were co-registered with high-spatial resolution images (3D gradient-echo T1-weighted sequence) covering both brain hemispheres. Preprocessing consisted of 3D movement correction, a 4-mm FWHM Gaussian spatial filter, and a temporal high-pass filter.

\section{Statistical analysis}

All data were analysed using SPSS 15.0 version (SPSS Inc., Chicago, IL, USA). First the Kolmogorov-Smirnov, Shapiro-Wilk and $\mathrm{c}^{2}$ tests at a $5 \%$ significance level were performed and the normal distribution hypothesis was rejected. Due to the small sample size, data was then analysed using non-parametric statistics: Mann-Whitney U tests for comparisons between groups and Wilcoxon tests for within group comparisons. Verbal learning and naming test scores and subjective memory questionnaire indices assessed one month after the completion of the rehabilitation program were the endpoints for analysis. The significance level was set at $\mathrm{p}<0.05$.

To determine the significance of changes in performance, each participant was classified as improved or not based on reliable change indices derived from normative data available from the Rey Auditory Verbal Learning Test and Boston Naming Test ${ }^{18,19,20}$.

The fMRI temporal series were analysed statistically using a general linear model with the evolution of each voxel being compared to a modelled reference function. In order to extend statistical inferences to the group level, the statistical maps of all subjects were registered to standard space and the significance of activation at each condition was nonparametrically evaluated using the paired Wilcoxon test for two related samples at $5 \%$ significance level for both voxels and cluster levels. The difference in the activation between the first and the second scan, between the second and the third, and between the first and the third scans were the indices used for the analysis. Threshold maps $(p<0.01)$ were superimposed on the structural images for anatomic reference.

\section{RESULTS}

\section{Objective cognitive outcomes}

There were no statistically significant differences between the groups on the first assessment for the objective cognitive measures.

Significant improvements were recorded following the rehabilitation program for verbal learning $(\mathrm{W}=2.38 ; \mathrm{p}=0.02)$; naming $(\mathrm{W}=2.32 ; \mathrm{p}=0.02)$ and on the Ecological Activity measure $(\mathrm{W}=2.34 ; \mathrm{p}=0.02)$. For the control group, improved performance was recorded only on the Ecological Activity measure $(\mathrm{W}=2 ; \mathrm{p}=0.05)$ (Table 3$)$.

Three participants in the rehabilitation group were classified as having improved memory on a basis of reliable change indices for verbal learning versus one participant in the control group. On the Boston Naming Test, two individuals were classified as having a meaningful improvement in naming versus none in the control group.

\section{Subjective memory outcomes}

The two groups were matched at the initial assessment on measures of self-perception and in the use of support strategies. Both subjective memory measures indicated improvements in the rehabilitation group (self perception: $\mathrm{W}=2.67$; $\mathrm{p}=0.008$ /strategies used: $\mathrm{W}=2.67 ; \mathrm{p}=0.008$ ). No changes were recorded for the control group (Table 3).

\section{fMRI}

There were no significant differences between the groups in activation patterns during the verbal fluency paradigm for the first fMRI scan. There were no changes between the first and the second scans for the rehabilitation group, but changes from the first to the third scan were observed in the right anterior prefrontal cortex $(\mathrm{W}=1.96 ; \mathrm{p}=0.05)$, pars opercularis of Brocas area in left hemisphere $(W=2.67 ; p=0.01)$, and in the right inferior prefrontal gyrus $(\mathrm{W}=2.43 \mathrm{p}=0.02)$. When the second scan was compared to the third scan there were changes in the right dorsal anterior cingulate cortex $(\mathrm{W}=2.07 ; \mathrm{p}=0.04)$ and in the left angular gyrus $(\mathrm{W}=2.21$; $\mathrm{p}=0.027$ ) (Figure).

Table 3. Control and rehabilitation group outcome measures.

\begin{tabular}{|c|c|c|c|c|}
\hline \multirow{2}{*}{ Variable } & \multicolumn{2}{|c|}{ Control } & \multicolumn{2}{|c|}{ Rehabilitation } \\
\hline & Pre & Post & Pre & Post \\
\hline \multicolumn{5}{|l|}{ Objective measures } \\
\hline Boston naming test & $37.4(7)$ & $37.3(6.1)$ & $38.3(11.6)$ & $42.8(8.2)$ \\
\hline Rey auditory verbal learning test & $44.7(9.1)$ & $45.8(7.9)$ & $45.4(7.4)$ & 48.7(6) \\
\hline Ecological activity (median/range) & $1 / 0-2$ & $1 / 1-2$ & $1 / 1-3$ & $2 / 1-3$ \\
\hline \multicolumn{5}{|l|}{ Subjective measures } \\
\hline Memory self perception & $40.7(11.9)$ & $41.9(13)$ & 43.2(13.6) & $37.9(13.7)$ \\
\hline Strategies used & $9.8(3.4)$ & $10(3.6)$ & $8.2(1.6)$ & $12.9(2.5)$ \\
\hline
\end{tabular}



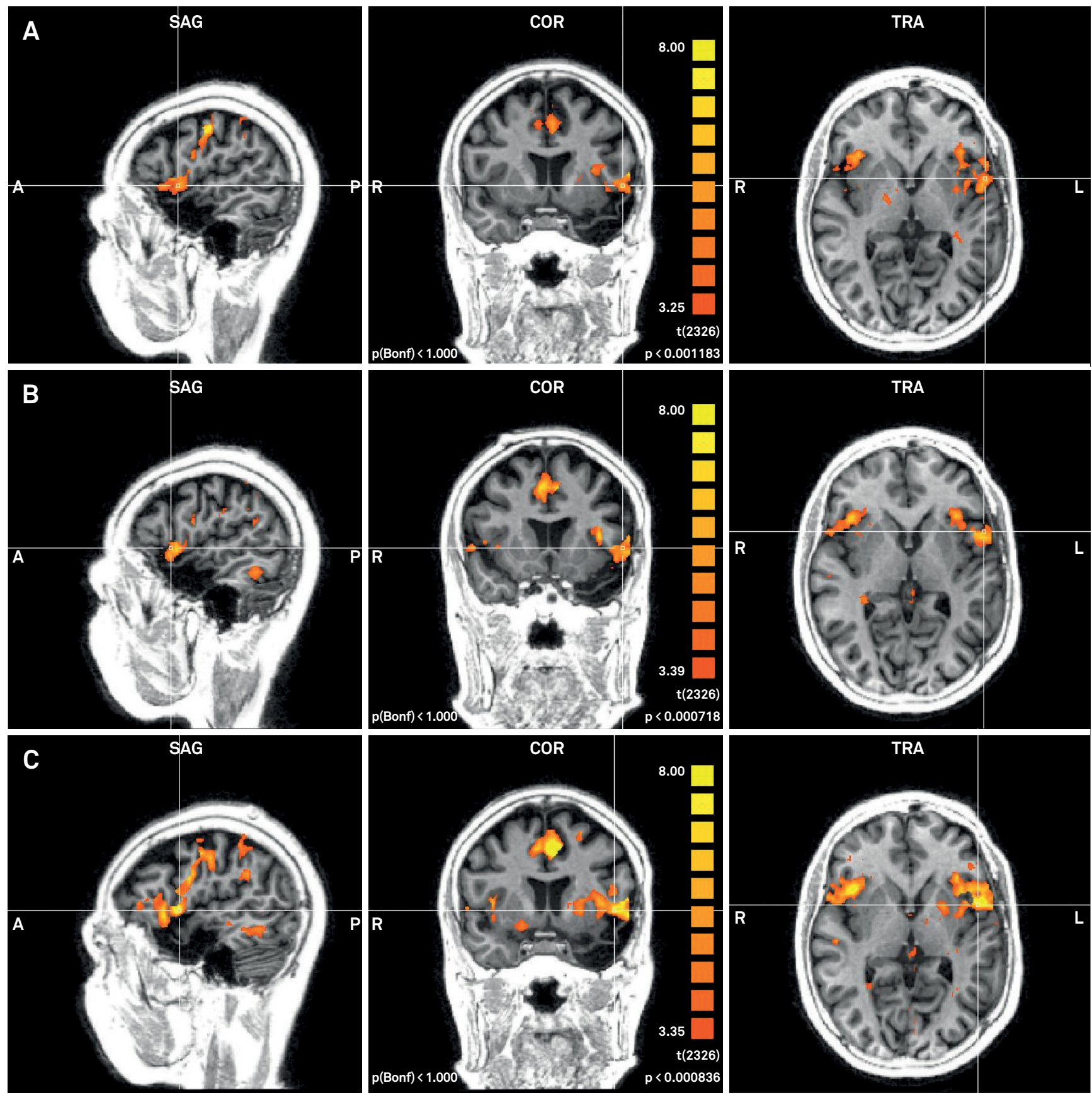

Figure. Activation pattern of language areas during fMRI word generation task in the rehabilitation group. A: before the intervention; B: one month after the program; C: three months after the program.

Activation pattern changes for the control group were observed from the first to the second scan in the primary somatosensory cortex $(\mathrm{W}=2.03 ; \mathrm{p}=0.04)$ and the left fusiform gyrus ( $\mathrm{W}=2.38 ; \mathrm{p}=0.02)$. Unfortunately, a third scan was not undertaken for technical reasons (Table 4).

\section{DISCUSSION}

Following a cognitive rehabilitation program, participants who were all post left temporal lobe surgery, showed improvements in memory and naming test scores and in
Table 4. Brain area activation.

\begin{tabular}{|c|c|c|c|}
\hline Group & Brain area & W & $p$-value \\
\hline \multicolumn{4}{|c|}{ Control group } \\
\hline \multirow[t]{2}{*}{$\operatorname{scan} 1 \times 2$} & Primary somatosensory cortex & -2.03 & $0.05^{\star}$ \\
\hline & Dorsal anterior cingulate cortex & -2.38 & $0.02 *$ \\
\hline \multicolumn{4}{|c|}{ Rehab group } \\
\hline $\operatorname{scan} 1 \times 3$ & Anterior prefrontal cortex & -1.96 & $0.05^{\star}$ \\
\hline $1 \times 3$ & Pars opercularis & -2.7 & $0.01 *$ \\
\hline $1 \times 3$ & Inferior prefrontal gyrus & -2.43 & $0.02 *$ \\
\hline $2 \times 3$ & Dorsal anterior cingulate cortex & -2.07 & $0.04^{\star}$ \\
\hline $2 \times 3$ & Superior temporal gyrus & -2.21 & $0.03 *$ \\
\hline
\end{tabular}


subjective ratings which, with the exception of one test score but with a very small significance $(p=0.05)$, were not observed in the controls. All but one individual, classified as demonstrating meaningful change based on reliable change indices, had received the memory training program. Changes in verbal fluency fMRI activation patterns were recorded following rehabilitation, but at the longer-term follow up.

Our findings support those reported by Jones et al. ${ }^{21}$ and Koorenhof et al. ${ }^{22}$ of improvements in verbal learning in left TLE surgery patients following strategy training. Bresson et al. $^{23}$, in presurgical cases, demonstrated improved verbal learning in association with training in the use of semantic strategies. Training-related improvements in objective measures of memory have been reported after group-based memory training.

We also found gains on a naming test following rehabilitation. Word-finding difficulties are a common complaint of people with TLE and naming decline has been observed in up to $60 \%$ of patients undergoing left anterior temporal lobe surgery ${ }^{24}$ and yet has rarely been the target of rehabilitation in epilepsy. Gess et al..$^{25}$ report on a patient who demonstrated the benefit of errorless learning on naming performance after temporal surgery. Minkina et al. ${ }^{26}$ reported naming improvements in a TLE patient after proper name retrieval training.

Participants in the rehabilitation group reported an increased use of memory strategies and a more positive perception of their memory. This suggests possible generalization from the program to daily life. Increased use of compensation strategies has previously been reported ${ }^{23,24,27}$. Improvements in subjective ratings of memory after cognitive training have been identified in a few studies ${ }^{9,22,24}$. We did not have any indication of the impact on quality of life and daily living skills and this is a shortcoming of the study.
Two months following the rehabilitation program, changes were recorded in left hemisphere networks involved in language, memory and attention and in right hemisphere networks involved in motivation ${ }^{28,29,30}$ that had not been apparent a month after completion. These changes may indicate a delayed positive impact of the rehabilitation program but this remains speculative due to the lack of a third scan in the controls. Changes in fMRI activation patterns observed in the controls were different and were apparent on the second scan and involved activation in the primary somatosensory cortex and the fusiform gyrus.

Our study has limitations. Participants were not randomly allocated: the control group consisted of patients who were unable to commit to the weekly rehabilitation sessions. We did not find differences in key demographic variables or initial cognitive performance levels but we cannot rule out that there were other possible differences between the groups. Our sample size was small and fell below our target set based on effect size analysis. Larger sample sizes would be required to have adequate power to detect change and to enable parametric analyses and consideration of predictor variables. However, performance changes were observed with the smaller numbers and we were also able to consider individual differences using reliable change indices. The lack of a third scan in the control group was a major limitation, which complicates the interpretation of the fMRI results.

However, this study provides support for the role of memory rehabilitation post-left temporal lobe surgery and the fMRI results are suggestive of accompanying changes in brain networks underlying the gains observed following rehabilitation. Our findings, we believe, are encouraging and indicate that rehabilitation should be considered as part of the surgical evaluation and preparation.

\section{References}

1. Thompson PJ, Koorenhof L, Kapur N. Memory rehabilitation for people with epilepsy. In: Zeman A, Kapur N, Jones-Gotman M, editors. Epilepsy and memory. Oxford: Oxford Press; 2012. p. 425-39.

2. Ownsworth TL, Mcfarland K. Memory remediation in long-term acquired brain injury: two approaches in diary training. Brain Inj. 1999;13(8):605-26. https://doi.org/10.1080/026990599121340

3. Butler RW, Copeland DR, Fairclough DL, Mulhern RK, Katz ER, Kazak AE et al. A multicenter randomized clinical trial of a cognitive remediation program for childhood survivors of a pediatric malignancy.J Consult Clin Psychol. 2008;76(3):367-78. https://doi.org/10.1037/0022-006X.76.3.367

4. Berry E, Kapur N, Williams L, Hodges S, Watson P, Smyth $\mathrm{G}$ et al. The use of a wearable camera, SenseCam, as a pictorial diary to improve autobiographical memory in a patient with limbic encephalitis: a preliminary report. Neuropsychol Rehabil. 2007;17(4-5):582-601. https://doi.org/10.1080/09602010601029780

5. Dewar BK, Wilson BA. Cognitive recovery from encephalitis lethargica. Brain Inj. 2005;19(14):1285-91. https://doi.org/10.1080/02699050500309536
6. Fisher M, Holland C, Merzenich MM, Vinogradov S. Using neuroplasticity-based auditory training to improve verbal memory in schizophrenia. Am J Psychiatry. 2009;166(7):805-11. https://doi.org/10.1176/appi.ajp.2009.08050757

7. Franck N, Demily C. [Improving functional outcome of schizophrenia with cognitive remediation]. Presse Med. 2015;44(3):292-7. French. https://doi.org/10.1016/j.lpm.2014.06.031

8. Radford K, Lah S, Thayer Z, Miller LA. Effective group-based memory training for patients with epilepsy. Epilepsy Behav. 2011;22(2):272-8. https://doi.org/10.1016/j.yebeh.2011.06.021

9. Engelberts NH, Klein M, Adèr HJ, Heimans JJ, Trenité DG, Ploeg HM. The effectiveness of cognitive rehabilitation for attention deficits in focal seizures: a randomized controlled study. Epilepsia. 2002;43(6):587-95. https://doi.org/10.1046/j.1528-1157.2002.29401.x

10. Helmstaedter C, Loer B, Wohlfahrt R, Hammen A, Saar J, Steinhoff BJ et al. The effects of cognitive rehabilitation on memory outcome after temporal lobe epilepsy surgery. Epilepsy Behav. 2008;12(3):402-9. https://doi.org/10.1016/j.yebeh.2007.11.010

11. Wilson BA. Rehabilitation of memory disorders. Horsham: Guilford Press; 2009 
12. Kaplan EF, Goodglass H, Weintraub S. The Boston naming test. Philadelphia: Lea \& Febiger; 1983.

13. Schmidt M. Rey Auditory Verbal Learning Test (RAVLT): A Handbook. Los Angeles: Western Psychological Services; 1996.

14. Stern RA, White T. Neuropsychological Assessment Battery (NAB). Lutz: Psychological Assessment Resources; 2003.

15. Trebuchon-Da Fonseca A, Guedj E, Alario FX, Laguitton V, Mundler $\mathrm{O}$, Chauvel $\mathrm{P}$ et al. Brain regions underlying word finding difficulties in temporal lobe epilepsy. Brain. 2009;132(10):2772-84. https://doi.org/10.1093/brain/awp083

16. Stuss DT, Alexander MP, Hamer L, Palumbo C, Dempster R, Binns $M$ et al. The effects of focal anterior and posterior brain lesions on verbal fluency. J Int Neuropsychol Soc. 1998;4(3):265-78.

17. Wilke M, Lidzba K, Staudt M, Buchenau K, Grodd W, Krägeloh-Mann I. An fMRI task battery for assessing hemispheric language dominance in children. Neuroimage. 2006;32(1):400-10. https://doi.org/10.1016/j.neuroimage.2006.03.012

18. Sawrie SM, Chelune GJ, Naugle RI, Lüders HO. Empirical methods for assessing meaningful neuropsychological change following epilepsy surgery.J Int Neuropsychol Soc. 1996;2(6):556-64. https://doi.org/10.1017/S1355617700001739

19. Bird CM, Papadopoulou K, Ricciardelli P, Rossor M, Cipolotti L. Monitoring cognitive changes: psychometric properties of six cognitive tests. Br J Clin Psychol. 2004;43(2):197-210. https://doi.org/10.1348/014466504323088051

20. Strauss E, Sherman EMS, Spreen O. A compedium of neuropsychological tests. 3rd ed. New York: Oxford University Press; 2006.

21. Jones MK, Imagery as a mnemonic aid after left temporal lobectomy: contrast between material-specific and generalized memory disorders Neuropsychologia. 1974;12(1):21-30. https://doi.org/10.1016/0028-3932(74)90023-2
22. Koorenhof L, Baxendale S, Smith N, Thompson P. Memory rehabilitation and brain training for surgical temporal lobe epilepsy patients: a preliminary report. Seizure. 2012;21(3):178-82. https://doi.org/10.1016/j.seizure.2011.12.001

23. Bresson C, Lespinet-Najib V, Rougier A, Claverie B, N'Kaoua B. Verbal memory compensation: application to left and right temporal lobe epileptic patients. Brain Lang. 2007;102(1):13-21. https://doi.org/10.1016/j.bandl.2006.06.005

24. Aldekamp AP, Hendriks MPH. Managing cognitive and behavioural consequences of epilepsy. In: Baker GA, Jacoby A, editors. Quality of life in epilepsy. Amsterdam: Harwood Academic; 2000. p. 27-40.

25. Gess JL, Denham M, Pennell PB, Gross RE, Stringer AY. Remediation of a naming deficit following left temporal lobe epilepsy surgery. Appl Neuropsychol Adult. 2014;21(3):231-27. https://doi.org/10.1080/09084282.2013.791826

26. Minkina I, Ojemann JG, Grabowski TJ, Silkes JP, Phatak V, Kendall DL. Treatment of proper name retrieval deficits in an individual with temporal lobe epilepsy. Am J Speech Lang Pathol. 2013;22(2):S250-5. https://doi.org/10.1044/1058-0360(2012/12-0048)

27. Aldenkamp AP, Vermeulen J, Neuropsychological Rehabilitation of memory function in epilepsy. Neuropsychol Rehabil. 1991;1(3):199-214. https://doi.org/10.1080/09602019108520165

28. Badre D, D’Esposito M. Functional magnetic resonance imaging evidence for a hierarchical organization of the prefrontal cortex.J Cogn Neurosci. 2007;19(12):2082-99. https://doi.org/10.1162/jocn.2007.19.12.2082

29. De Baene W, Albers AM, Brass M. The what and how components of cognitive control. Neuroimage. 2012;63(1):203-11. https://doi.org/10.1016/j.neuroimage.2012.06.050

30. MacDonald AW 3rd, Carter CS. Event-related FMRI study of context processing in dorsolateral prefrontal cortex of patients with schizophrenia. J Abnorm Psychol. 2003;112(4):689-97. https://doi.org/10.1037/0021-843X.112.4.689 